\title{
TISSUE CULTURE AS A POSSIBLE AID IN RECOGNIZING THE ORIGIN OF CYSTIC HYGROMA*
}

\author{
BY \\ JOHN GRIEVE and JOHN D. B. MACDOUGALL \\ From the Departments of Surgery and Anatomy, Queen's College, Dundee (University of St. Andrews)
}

For many years the neck and the axilla in the child have been recognized as the commonest sites for cystic hygroma. Goetsch (1938) gave an extensive clinical and pathological survey of this condition and reported 12 fresh cases of varying ages. Recently two cases have been seen in the Royal Infirmary, Dundee, which behaved clinically in quite different ways.

Tissue culture was used by Sano and Bello (1949) as a means of differentiating morphologically identical cells in lymph nodes. In the light of this and of the reputed lymphatic origin of cystic hygroma we have successfully grown material from an axillary hygroma. This appears to be the first occasion on which this has been achieved.

\section{Material}

Both babies were girls. The first (Fig. 1) was seen within 48 hours of birth when the very large swelling was not interfering with either respiration or feeding. The tumour could be transilluminated readily and the clinical appearance was that of a cervical cystic hygroma. No immediate treatment was advised. Over the months the tumour rapidly regressed and at 8 months showed only surplus skin and a tiny nodule $0.5 \mathrm{~cm}$. in diameter left in the neck.

The second infant had a cystic swelling in the left axilla which extended forward from the mid-axillary line to the region of the left nipple. It had been present since birth and slowly but steadily increased in size until at 6 months of age the tumour measured approximately $8 \mathrm{~cm}$. by $5 \mathrm{~cm}$. with a small firm nodule $1 \mathrm{~cm}$. in diameter near the centre. Again it could be transilluminated and the clinical appearance was that of an axillary cystic hygroma. On March 5, 1956, wide excision was done and the cysts emptied and the raw surfaces swabbed with carbolic. Histological sections reported on by Dr. Wallace Park

\footnotetext{
* A paper presented at the meeting of the British Association of Paediatric Surgeons in London in July, 1956. This is a preliminary communication.
}

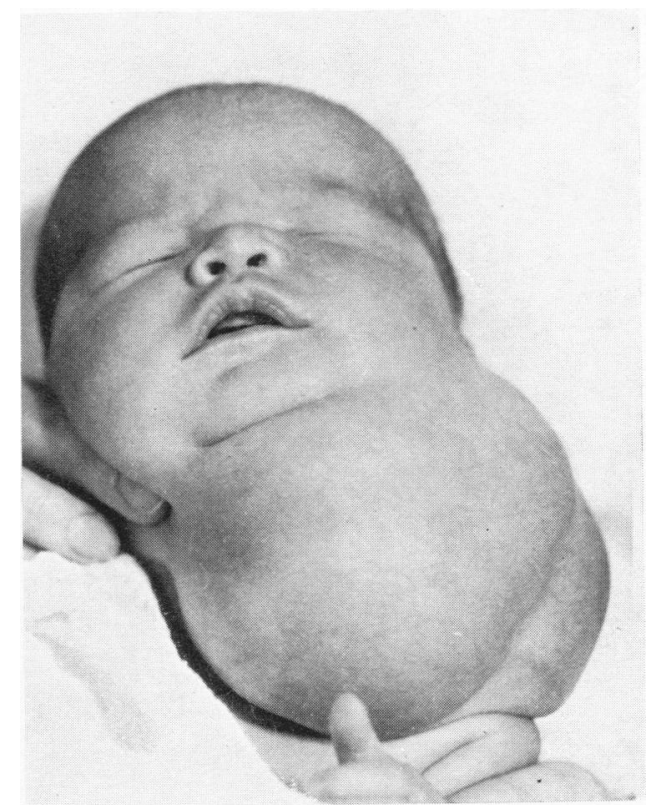

FIG. 1.-Large cervical cystic hygroma which regressed over a period of three months.

showed the features of a cystic hygroma with endothelial lined spaces in a fibro-fatty framework and no significant quantity of lymphatic tissues in the area examined (Fig. 2). A representative piece of tissue was selected for tissue culture and rapidly transferred to the laboratory.

\section{Tissue Culture Technique and Results}

Ten pieces of tissue were put up in standard hanging drops using equal parts of plasma and embryonic extract. They were incubated for 48 hours at $37^{\circ} \mathrm{C}$ and showed no evidence of growth.

A further six pieces of tissue were placed in roller tubes according to the method of Cameron (1950), and $0.7 \mathrm{ml}$. of supernatant fluid, censisting of $50 \%$ tyrode solution, $30 \%$ horse serum and $20 \%$ embryonic extract, was added to each tube and they were rotated at 12 revolutions per 


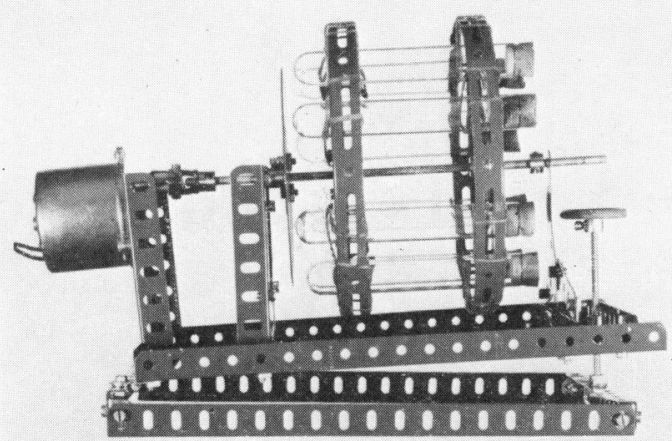

FIG. 3 .
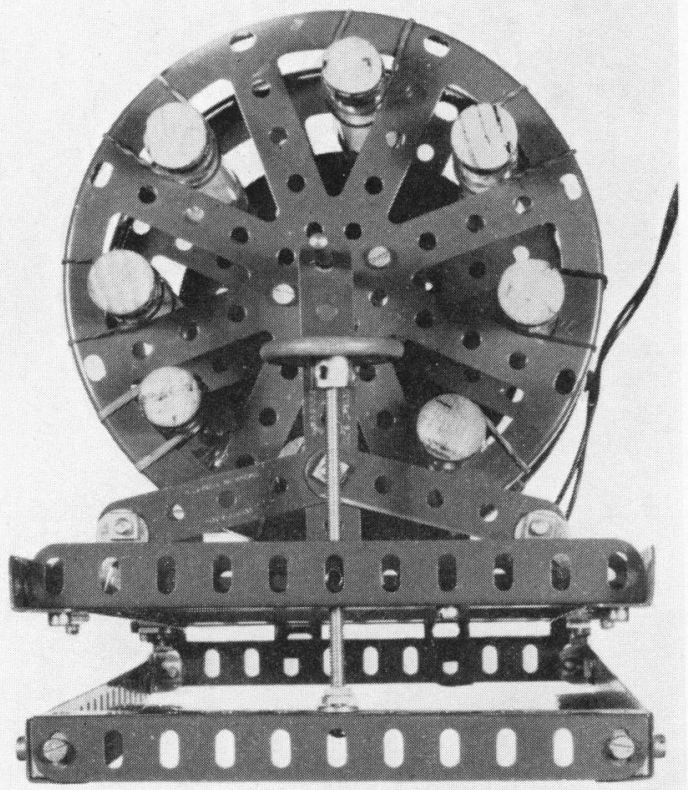

FIG. 4.

FIG. 2.-Histological section (low power) from axillary cystic hygroma -also used for tissue culture.

FIG. 3.-General view of apparatus for rolling tubes.

FIG. 4.-End-on view showing disposition of tubes in same apparatus as Fig. 3.

FIG. 5.-Low magnification view of growing explant.
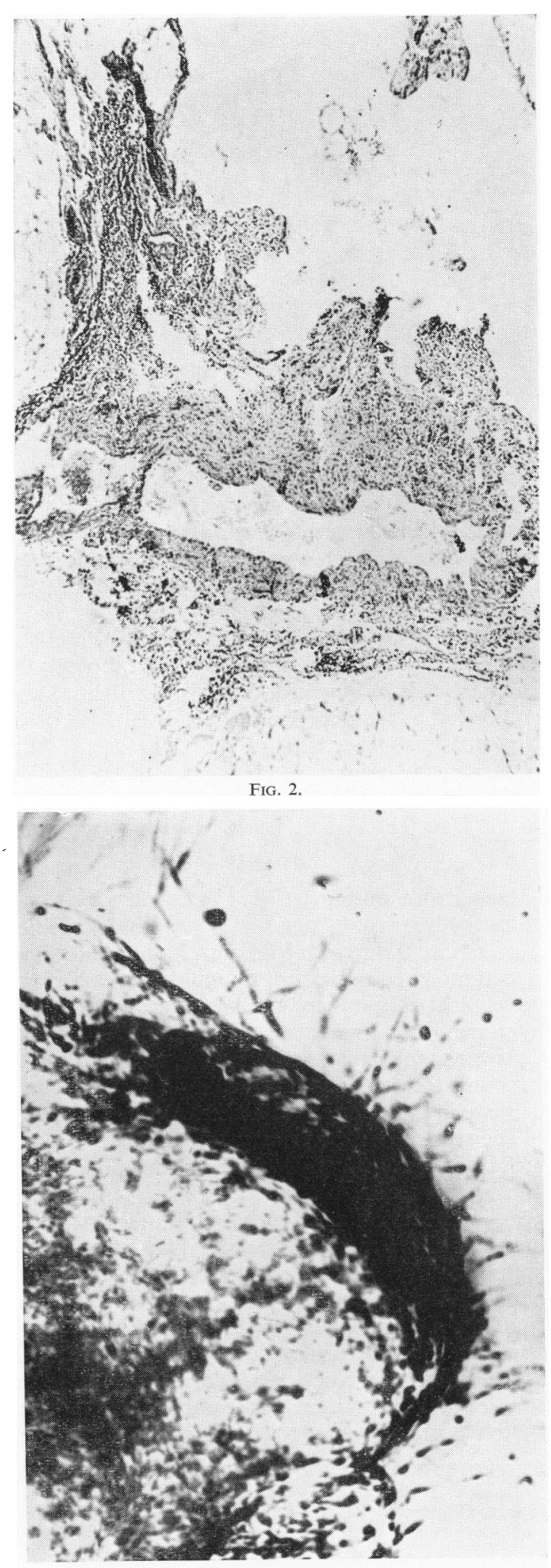

FIG. 5. 
hour in the drum arrangement shown in Figs. 3 and 4. This small roller tube drum followed the design of Szabó (1956) but was constructed from 'meccano'. Culture was continued for four days and three of the explants showed growth (Fig. 5). Finally the explants with growth were fixed and stained in situ. Microscopic examination of the proliferating cells showed pleomorphism.

\section{Discussion}

These two infants demonstrated opposite behaviour in two apparently similar lesions. It has usually been assumed that a cystic hygroma represented a maldevelopment of lymphatics at the site of occurrence. In the first infant the spontaneous regression could be explained on the basis of a multilocular cyst with communications between the loculi and one or two ultimate drainage channels. Such a state of affairs is occasionally seen in multilocular solitary cysts of the kidney. Wynn-Williams and Morgan (1950) reported a lymphangiomatous solitary cyst of kidney but study of their report and of material from a similar case (Attwood and Grieve, 1956) does not confirm the lymphangiomatous nature of these renal cysts.

The differing behaviour in the second child could be explained by the macroscopic and microscopic demonstration of a very large number of cysts varying in size from $1 \mathrm{~mm}$. or less to around $1 \mathrm{~cm}$. in diameter. Nothing about the structure suggested communication between the cysts.

Sano and Bello's work indicated that tissue culture might throw light on the origin of the lining cells. Using a simple roller-tube technique vigorous growth was obtained in three of the explants made. The cells were pleomorphic but their exact nature has not yet been determined.

\section{Summary}

The differing behaviour of an axillary and a cervical cystic hygroma has been described. With a simple roller tube tissue culture technique explants from the axillary tumour have been grown successfully. Pleomorphism was present in the outgrowths. Some of the cells were fibroblasts but the others have not yet been identified.

The cervical hygroma disappeared spontaneously and the possible similarity in structure to certain renal cysts has been emphasized. There was, however, no evidence to suggest that such renal cysts were lymphangiomatous in nature.

Mrs. Agnes Halley, Department of Anatomy, gave invaluable technical assistance and Miss Allison Thomson and Mr. Murray Ettle, Department of Surgery, were responsible for the manuscript and photography respectively.

\section{REFERENCES}

Attwood, H. D. and Grieve, J. Unpublished data.

Cameron, Gladys (1950). Tissue Culture Technique, 2nd ed. New York.

Goetsch, E.. (1938). Arch. Surg. (Chicago), 36, 394.

Sano, M. E. and Bello, C. T. (1949). Amer. J. Med., 6, 509.

Szabó, G. (1956). Personal communication.

Wynn-Williams, D. and Morgan, A. D. (1950). Brit.J. Surg., 37, 346 